Desoete Annemie, Ceulemans Annelies, Sofie Rousseau, and Mathieu Roelants

\title{
The relative importance of "parental talk" as a predictor of the diversity in mathematics learning in young children
}

\begin{abstract}
This study explored the importance of the amount of "parental talk" focusing on numerical cues as "opportunity factor" in the prediction of diversity in mathematics learning. Thirty-one children were followed up from toddlerhood (24 months of age) till kindergarten (48 months of age). Mathematics learning was tested with a number discrimination task at 24 months. At 48 months children's mathematics learning was examined with a procedural and conceptual counting task and a calculation task. The amount of parental talk was operationalized via a questionnaire and via a structured play Duplo or Lego building session. The study confirmed a substantial amount of diversity in the frequency of parental talk with the results of the questionnaire and the observation positively related to each other. A positive concurrent association was found between the amount of observed parental talk and children's calculation skills in kindergarten. Parental talk with toddlers was also positively predicting children's mathematics learning in kindergarten. There was a trend of positive association between the amount of parental talk with toddlers and children's conceptual counting abilities in kindergarten. There was a positive quadratic predictive contribution of parental talk in toddlers for "calculation" in kindergarten. These results confirmed that mathematics learning might not be unitary even in young children and that parental talk should be considered as one of the opportunity factors to explain some of the diversities in mathematics learning.
\end{abstract}

Keywords: parental talk, opportunity-propensity model, toddlers, kindergartners, mathematics learning, number discrimination, procedural counting, conceptual counting, calculation

\section{Introduction}

\subsection{Mathematics learning}

Nelson and Powell (2018) revealed findings based on 35 longitudinal studies that mathematics learning in elementary school was one of the biggest predictors

Ә Open Access. (C) 2021 Desoete Annemie et al., published by De Gruyter. (c) BY-NC-ND This work is licensed under the Creative Commons Attribution-NonCommercial-NoDerivatives 4.0 International License. https://doi.org/10.1515/9783110661941-007 
for future academic achievement. Mathematics skills were stronger predictors than reading skills, even after controlling for intelligence and socioeconomic status. Deary et al. (2000) demonstrated diversity in mathematics learning from childhood to old age. A longitudinal study on 17.638 participants revealed that mathematics learning at the age of seven was positively associated with the socioeconomic status (SES) of individuals at the age of 42 years. This effect was significant even when controlling for intelligence and SES at birth on top of intelligence and SES at birth (Ritchie \& Bates, 2013). Poor mathematics learning was revealed to have an impact on daily life, resulting in more employment in low paid professions and in negative consequences for (mental) health (Duncan \& Magnuson, 2011; Geary, 2011; Wilson et al., 2015). These studies indicated the importance of mathematics and indicated the need to improve the understanding of mathematics learning, and in particular diversity in mathematics learning.

\subsection{Mathematics learning in young children}

Mathematics learning might not be unitary, but is rather made up of many different subcomponents, such as number discrimination, counting procedures, counting principles, and calculation with possible discrepancies among subcomponents (Dowker et al., 2019).

According to Clements and Sarama (2014) there is no age too young for mathematical thought. Number discrimination can be seen as an early marker of diversity in infants ( $\mathrm{Xu} \&$ Arriaga, 2007). Previous research has shown that number discrimination in toddlerhood even has some predictive value for mathematical learning in kindergarten (Ceulemans et al., 2015, 2017).

Previous studies also revealed that children's counting proficiency played a role in the development of mathematics learning. A secondary analysis on 7,665 children indicated that counting was one of best predictors of school success (Claessens \& Engel, 2013). The knowledge of counting procedures (or procedural knowledge) and the knowledge of counting principles (conceptual knowledge) can be seen as two distinctive aspects of counting. Procedural counting knowledge is needed to determine that there are five objects in an array. Conceptual counting knowledge reflects a child's understanding of the essential counting principles: the stable order principle, the one-one-correspondence principle and the cardinality principle (Desoete \& Roeyers, 2009; Stock et al., 2009).

Finally, mathematics learning also involves basic knowledge and skills to calculate accurately in order to solve mathematical tasks. In later years, not only calculation accuracy but also calculation fluency will be needed (LeFevre et al., 2009). 


\subsection{Opportunity (O)-Propensity (P) model to explain diversity}

The Opportunity-Propensity (O-P) framework (Byrnes, 2020; Byrnes \& Miller, 2016; Wang et al., 2013) aims to explain some of the diversity of mathematical learning, visualized in Fig. 1.

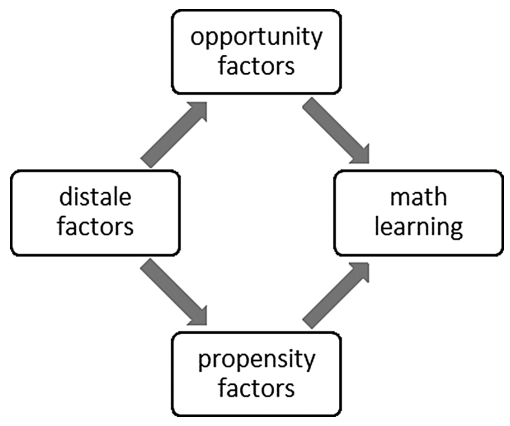

Fig. 1: The Opportunity-Propensity model.

Propensity factors $(\mathrm{P})$ in the O-P model refer to the variables that make people able (e.g., intelligence) and/or willing (e.g., motivation) to learn mathematics. Opportunity factors $(\mathrm{O})$ have been defined as contexts and variables that expose children to learning content (e.g., home and school environment, including parental talk). Distal variables (e.g., SES) were included in the model to explain why some people are exposed to richer opportunity contexts and have stronger propensities for learning than others.

The O-P model has been validated in large secondary data sets, including lower-income pre-kindergarten children, children followed up from kindergarten until primary school and secondary school pupils (Byrnes, 2020; Byrnes \& Miller, 2016; Wang et al., 2013). These studies have shown that mathematics learning (as outcome variable) improved with more propensities (P-factor). In addition, some of the diversity in mathematical learning could be explained by the opportunities in the school and home environment (O-factors).

Previous studies informed us about the information on the influence of the school environment (Baten \& Desoete, 2018; Byrnes \& Miller, 2016) in the prediction of mathematics learning. The impact of these school related O-factors depended on the specific support factors (Byrnes \& Wasik, 2007, 2009). However, other studies have shown that the home numeracy environment also mattered (as O-factor) for mathematics learning (Missall et al., 2014; Segers et al., 2015). Parent-child interactions that included experiences with numerical content in daily life have been positively associated with children's mathematics learning 
(e.g., Blevins-Knabe \& Austin, 2016). Anders et al. (2012) demonstrated that the quality of the home environment at the beginning of kindergarten (mean age of 3 years) was strongly associated with mathematics learning in preschool, with this advantage maintained at the end of preschool (mean age 5 years). Their results underlined the differential impact of school and home environments on mathematics learning. Niklas et al. (2016) and Casey et al. (2018) demonstrated that offering more parental support to children resulted in better mathematics learning. Kindergartners who received rich early numerical home opportunities developed better mathematics skills compared to those with fewer learning opportunities (e.g. Clements \& Sarama, 2014; Kleemans et al., 2012; LeFevre et al., 2009). However, Yildiz et al. (2018) found that home numeracy factors operationalized in a questionnaire (parent's reports) were positively related to children's calculation abilities, on the other hand, contrary to expectation, the observed parental talk was negatively related to children's calculation abilities. They concluded that questionnaires and observations might tap different aspects of home numeracy.

\subsection{Parental talk as Opportunity (0) factor}

Some component of the association between home environment and mathematics learning might be at least partially explained by parental involvement (Hong et al., 2010; Wilder, 2014) or by parental responsiveness (Dieterich et al., 2006). Parental involvement can be described as the overall quality of the interaction between parent and child (e.g., Melhuish \& Phan, 2008; Sy et al., 2013). In addition, some studies revealed that also parental responsiveness was positively associated with later language and literacy development of children (e.g., Dieterich et al., 2006). On top of the constructs involvement and responsiveness, math-related parental talk is a component of home numeracy (e.g., Karrass \& Braungart-Rieker, 2005).

Parental talk can be defined as the formal or direct numeracy talk (such as counting objects) and informal or indirect (such as mealtime) numeracy talk of parent-child dyads. Susperreguy and Davis-Kean (2016) revealed that all mothers involved their preschool child in a variety of math exchanges during mealtime, although there were differences in the amount of input that children received. Several studies have shown that parental talk often involved counting and labeling cardinal values of sets (Ramani et al., 2015; Zhou et al., 2006). Talking about large sets of objects was the strongest predictor of mathematics learning (Gunderson \& Levine, 2011). 


\subsection{Diversity in parental talk and in subcomponents of mathematics learning}

Dowker (2019) has shown that mathematics learning might not be unitary and may differ with age. A study in kindergarten, grades 1 and 2, revealed that basic numerical skills were positively associated with informal parental talk, whereas calculation fluency was related to both formal and informal parental talk (LeFevre et al., 2009). Yildiz et al. (2018) confirmed the positive relationship between parental talk and calculation in the last year of kindergartners (mean age 5.64 years), but only with the parental talk assessed via a questionnaire. Levine et al. (2011) demonstrated that in 14- to 30-month-olds the frequency of parental talk about numbers predicted the children's cardinal knowledge (e.g., knowing that the word "four" refers to sets with four items) at 46 months of age. The study of Skwarchuk et al. (2014) indicated that formal talk (such as practicing sums) predicted symbolic number system knowledge, whereas informal talk was related to children's abilities to non-symbolically represent and manipulate quantities in children starting in kindergarten (mean age 58 months). Benavides-Varela et al. (2016) provided evidence for the unexpected finding that the construct "home environment" was related to the exact, but not to the approximate, number representation in children with a mean age of 5 years 11 months. Casey et al. (2018) found that (observed) parental support (labeling sets of objects) at 36 months predicted mathematics learning at $4 \frac{1}{2} 2$ and 6-7 years.

To conclude, although there is evidence that parental talk is predictive for mathematics learning, the importance might depend on the age of children, on the subcomponent of mathematics learning that is studied, and even on the technique that is used to operationalize parental talk and mathematics learning.

\subsection{Current study}

In this study we use questionnaires and observations to assess parental talk and to study the association with mathematics learning in toddlers and in kindergarten. This results in the following specific Research Questions (RQ).

RQ1. Is there diversity in the parental talk with young children? Are questionnaires and observations of parental talk positively associated?

RQ2. Is there diversity in mathematics learning assessed at 24 months (with a number discrimination task) and at 48 months (with procedural and conceptual counting tasks and a calculation task)?

RQ3. Does parental talk predict mathematics learning, controlling for parental involvement and sensitivity? 


\section{Method}

\subsection{Participants}

Participants were part of a birth cohort, living in different Flemish districts in Belgium. They were recruited within the scope of a longitudinal study for the Belgian government (www.steunpuntwvg.be). A small sample of children were randomly selected to participate in a more in depth study on mathematics learning (see also Ceulemans et al., 2015, 2017). As such, parents of 15 boys and 16 girls consented to participate with their child at the age of 24 (T1) and 48 months (T2). The mean intelligence of the children measured with Wechsler Preschool and Primary Scale of Intelligence - Third edition (WPPSI-III-NL; Wechsler, 2002; Dutch translation) was $101.33(S D=12.53)$. Half of the families of the children had a middle income and the other half had a high income when the research project started. The category "middle income" comprised a considerable part of the study population being a "modal" family with two working parents as manual worker or employee. Families in the "middle income" category earned between 1,501 and 3,000 euros, whereas those in the "high income" category earned more than 3,000 euros per month.

\subsection{Procedure and analyses}

Linear regression analyses were conducted to explore the research questions. Graphical inspection of the data revealed that error terms were normally distributed. Since not only the quantity of opportunities might be important, linear and quadratic relationships were explored. Only in case of a significant quadratic relationship was this mentioned additional to the results of the linear relationship between certain variables. Moreover, significant relationships between the opportunities were tested by taking into account the control variable (parental involvement and sensitivity).

\subsection{Instruments}

\subsubsection{Parental talk (0-factor)}

Parental talk was tested through observations and via a questionnaire. The structured play situation was used to observe "parental talk" (as O-factor) at 24 and 48 months. Mother and child sat on a carpet and were instructed to build a 
house with a set of Duplo blocks according to a model. After the instruction was given, parent and child were left alone in the room. The structured play was recorded for five minutes on video and all parental talk, and/or language of the children were coded manually afterward. All actions were given a score according to their frequency during the observation. The sum of all scores (which could be reduced to 18 items) resulted in the total parental talk score. Internal consistency of the data output was .63 $(M=55.51, S D=29.71)$. At 24 months two experimenters achieved an averaged inter-rater reliability of .88 percentage of scores in agreement. At 48 months two experimenters achieved an averaged inter-rater reliability of .84 percentage of agreement.

All parents also completed questionnaires. The questionnaire on parental talk included activities related to mathematics learning at home, with 13 items related to direct activities (such as learn the right sequence of number words) and 10 items related to indirect activities (such as sing a song with numbers). Parents were asked to score all items according to their occurrence during the past month. They could choose between the options never (1), sometimes (2), or many times (3). The option "not applicable" (0) could be indicated when parents thought that their child could not perform this behavior because he/she was not yet able to do it. The original options to indicate frequency were transformed into scores ranging from zero to two per item. Cronbach's alpha was .87 (with .85 for the direct activities and .72 for the indirect activities). For the mean (M) and standard deviation (SD) of all items, see Tab. 1.

Tab. 1: Diversity in (self-reported) parental talk of todlers.

\begin{tabular}{|c|c|c|c|c|c|c|}
\hline & \multicolumn{6}{|c|}{ Response options (\%) } \\
\hline & 0 & 1 & 2 & 3 & $M$ & $(S D)$ \\
\hline \multicolumn{7}{|l|}{ Direct activities } \\
\hline Use words about quantity and size & 5.56 & - & 33.33 & 61,11 & 2.50 & $(0.79)$ \\
\hline Use words to compare & 11.11 & 5.56 & 27.78 & 55.56 & 2.28 & $(1.02)$ \\
\hline Use number words: one, two, three & - & - & 33.33 & 66.67 & 2.67 & $(0.49)$ \\
\hline Use number words: four, . . ., ten & 11.11 & 27.78 & 27.78 & 33.33 & 1.83 & (1.04) \\
\hline $\begin{array}{l}\text { Say the sequence of numbers from } \\
\text { one to ten }\end{array}$ & 5.56 & 27.78 & 33.33 & 33.33 & 1.94 & $(0.94)$ \\
\hline $\begin{array}{l}\text { Learn the right sequence of number } \\
\text { words }\end{array}$ & 11.11 & 38.89 & 22.22 & 27.78 & 1.67 & $(1.03)$ \\
\hline $\begin{array}{l}\text { Learn counting or say number words } \\
\text { using fingers }\end{array}$ & 11.11 & 55.56 & 27.78 & 5.56 & 1.28 & $(0.75)$ \\
\hline
\end{tabular}


Tab. 1 (continued)

\begin{tabular}{|c|c|c|c|c|c|c|}
\hline & \multicolumn{6}{|c|}{ Response options (\%) } \\
\hline & 0 & 1 & 2 & 3 & $M$ & $(S D)$ \\
\hline Encourage counting & 5.56 & 44.44 & 33.33 & 16.67 & 1.61 & $(0.85)$ \\
\hline Asking "how many" & 5.56 & 55.56 & 27.78 & 11.11 & 1.44 & $(0.78)$ \\
\hline Practice counting objects & 5.56 & 33.33 & 50.00 & 11.11 & 1.67 & $(0.77)$ \\
\hline Encourage use of matching & 5.56 & 5.56 & 66.67 & 22.22 & 2.06 & $(0.73)$ \\
\hline Recognizing and naming numbers & 22.22 & 77.78 & - & - & 0.78 & $(0.43)$ \\
\hline Counting down & 11.11 & 11.11 & 44.44 & 33.33 & 2.00 & $(0.97)$ \\
\hline \multicolumn{7}{|l|}{ Indirect activities } \\
\hline Name shapes & 11.11 & 44.44 & 44.44 & - & 1.33 & $(0.69)$ \\
\hline Sort objects on color & 11.11 & 27.78 & 55.56 & 5.56 & 1.56 & $(0.78)$ \\
\hline Sort objects on shape & 11.11 & 50.00 & 33.33 & 5.56 & 1.33 & $(0.77)$ \\
\hline Sort objects on size & 11.11 & 72.22 & 16.67 & - & 1.06 & $(0.54)$ \\
\hline Sing a song on numbers & 11.11 & 33.33 & 27.78 & 27.78 & 1.72 & $(1.02)$ \\
\hline $\begin{array}{l}\text { Give compliments to child on using } \\
\text { numbers }\end{array}$ & 11.11 & 27.78 & 27.78 & 33.33 & 1.83 & $(1.04)$ \\
\hline $\begin{array}{l}\text { Play with magnetic numbers or } \\
\text { number stamps }\end{array}$ & 11.11 & 72.22 & 11.11 & 5.56 & 1.11 & $(0.68)$ \\
\hline Read books with focus on numbers & 16.67 & 33.33 & 44.44 & 5.56 & 1.39 & $(0.85)$ \\
\hline Play with a dice & 22.22 & 55.56 & 22.22 & - & 1.00 & $(0.69)$ \\
\hline Measure ingredients & 22.22 & 38.89 & 27.78 & 11.11 & 1.28 & $(0.96)$ \\
\hline
\end{tabular}

\subsubsection{Parental involvement and parental sensitivity}

All parents completed a questionnaire with 10 items on parental involvement from the scale "Parental Involvement in Developmental Advance (PIDA)" of the StimQ-Toddler interview (Dreyer et al., 1996) were included. These items described possible actions or activities with the child initiated by the parent in the home environment. Cronbach's $\alpha(\mathrm{M}=10, S D=1.41)$ in the present study was .71 at 24 months and .63 at 48 months. A pilot study showed that the questionnaire was easy to complete.

During observation of the structured play parental sensitivity was measured as well. In line with other research (e.g., Feldman \& Masalha, 2010), the 
Coding Interactive Behavior (CIB) system (Feldman, 1998) was used to assess the parental sensitivity during the structured play. This is a global rating system of parent-child interaction that included 42 codes rated on a scale of 1 (low) to 5 (high) that leads to eight theoretically derived parent, child, and dyadic composites on diverse aspects of parent-child interaction. For each code, the observer assigned a single score after viewing the entire interaction, and several viewings were required to complete the coding. At 24 months the coder achieved an averaged percentage of agreement of .84 with an officially trained coder by the laboratory of Feldman. At 48 months the inter-rater reliability between two observers averaged .91 with the same trained coder. The composite set of parental sensitivity indicators was used in this study. This composite set included the codes "parent acknowledgment of child signals," "maintenance of visual contact," "expression of positive affect," "appropriate vocal quality," "resourcefulness in handling child's distress or expanding the interaction," "consistency of style," and "display of an affective range that matches the infant's readiness to interact." Reliability as measured with Cronbach's $\alpha(M=3.96, S D=0.55)$ for this composite set of indicators in the present study was .87 at 24 months and .80 at 48 months.

\subsubsection{Mathematics learning}

Mathematics learning was assessed as an outcome variable (at 24 and 48 months) in the O-P model.

Mathematics learning at 24 months was tested with a number discrimination task using a manual search paradigm as described by Feigenson and Carey (2005). A wooden box $(25 \mathrm{~cm} \times 12.5 \mathrm{~cm} \times 31.5 \mathrm{~cm})$ had a slit at the front oriented toward the toddlers and an opening at the backside oriented toward the experimenter who was facing the child at an - except for the box - empty table. Parents were told that some balls would be hidden to explore how children responded to a task and that no wrong reaction existed. The task entailed three kinds of trials: a first box empty trial, a more remaining trial, and a second variant of the box empty trial, which always followed after a more remaining trial (see Fig. 2).

Each of the trial types was presented twice and the order of the trials was counterbalanced. Children could search through the slit for 10 seconds after each type of trial commenced. It was expected that children would search longer after the more remaining than after the box empty trials which would indicate successful discrimination. Cumulative searching time was coded. Subtracting searching time after box empty trials from searching time after more remaining trials resulted in difference scores. Reliability of the difference scores, as measured with Cronbach's $\alpha$, was .79 for this task $(\mathrm{M}=2.42, S D=1.48)$. 


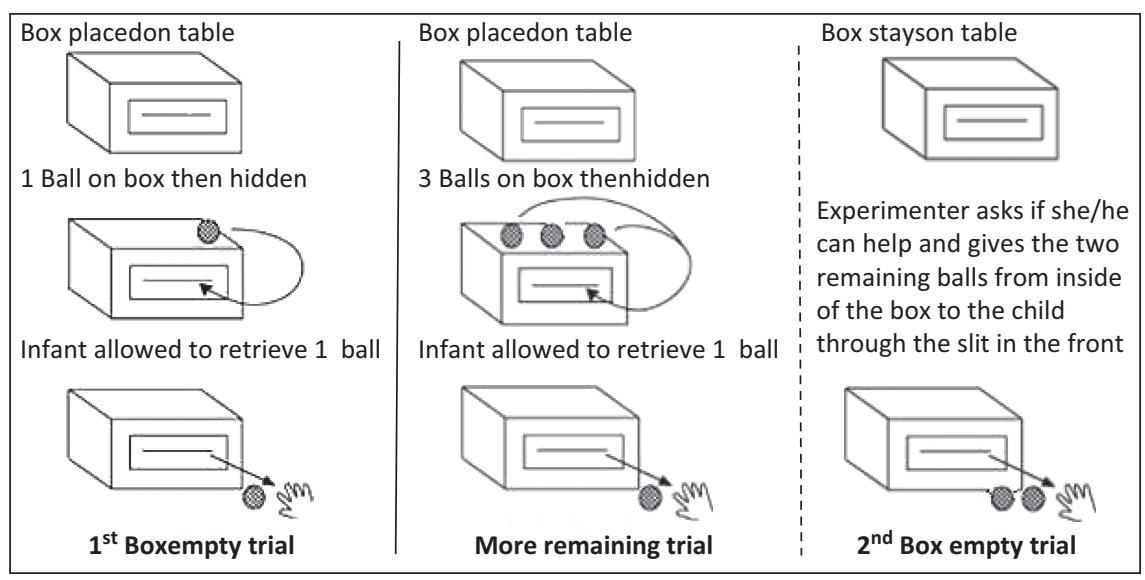

Fig. 2: Different trial types of the manual search task. Adopted from "On the limits of infants' quantification of small object arrays," by Feigenson and Carey (2005), Cognition, 97, p. 301. Copyright 2004 by Elsevier B.V.

Mathematics learning at 48 months was tested with three subtests of the TEDI-MATH (Grégoire et al., 2004). Procedural counting was tested with all eight items of TEDI-MATH where children had to count starting from one (up till 31), counting up to an upper bound (e.g., "count to 9") and/or from a lower bound (e.g., "count from 3"). Cronbach's $\alpha$ of the current study was .62 (M $=1.45, S D=$ 1.61). Conceptual counting was tested with all 13 items of TEDI-MATH where children had to judge the counting of linear and non-linear patterns of objects, and were asked questions about the counted amount of objects (e.g., "How many objects are there in total?"). Furthermore, they had to construct two numerical equivalent amounts of objects and use counting as a problem-solving strategy in a riddle. Cronbach's $\alpha$ of the current study was .76 $(\mathrm{M}=4.39, S D=$ 2.70). Calculation was tested with all six items of TEDI-MATH where children had to solve visually supported additions and subtractions. Reliability for the current study was Cronbach's $\alpha=.73(\mathrm{M}=1.97, S D=1.80)$.

\section{Results}

\subsection{Diversity in "parental talk"}

The amount of "parental talk" (assessed with a questionnaire) was positively associated with the amount of observed "parental talk" (during the manual search task) 
with $r=.54$, $(p<.001)$. Table 1 gives an overview of the frequencies of the parental talk assessed via a questionnaire at 24 months. "Using words to tell something about the quantity or the size of objects," "using words to express a comparison between objects," and "using the small number words from one to three" were the most frequent activities by parents of toddlers. Direct "opportunities" to focus on mathematics learning were reported as occurring (i.e., either "sometimes" or "many times") in about $60 \%$ of the cases. Indirect "opportunities" to focus on mathematics learning were reported as not occurring in about $60 \%$ of the cases.

During the observation of parental talk (the structured play) interactions using Duplo or Lego blocks occurred on average with a frequency of about 31.21 times $(S D=14.34$, range $=0.00-58.00)$ during the observation which lasted 5 min, giving a rate of about 6 interactions per minute. Only once was no parental talk between mother and child observed during the structured play situation, again pointing to diversity of opportunities offered by children to enhance mathematics learning.

\subsection{Diversity in mathematics learning}

There was no significant association (see Tab. 2) between mathematics learning in toddlers (assessed with a number discrimination task) and in kindergarten (assessed with a counting and calculation task). Counting and calculation skills were positively and significantly associated (at 48 months).

Tab. 2: Correlations between mathematics learning measures.

\begin{tabular}{|c|c|c|c|c|c|c|}
\hline Mathematics learning & $\begin{array}{l}1 \\
24 \text { month }(\mathrm{m})\end{array}$ & $\begin{array}{l}2 \\
48 \mathrm{~m}\end{array}$ & $\begin{array}{l}3 \\
48 \mathrm{~m}\end{array}$ & $\begin{array}{l}4 \\
48 \mathrm{~m}\end{array}$ & $M$ & (SD) \\
\hline 1. Number discrimination & - & & & & 1.45 & (1.43) \\
\hline 2. Procedural counting & -.03 & - & & & 1.45 & (1.61) \\
\hline 3. Conceptual counting & -.03 & $.38^{\star}$ & - & & 4.39 & $(2.70)$ \\
\hline 4. Calculation & -.07 & $.41^{\star}$ & $.57^{\star \star}$ & - & 1.97 & $(1.80)$ \\
\hline
\end{tabular}

\subsection{Relation between parental talk (as "opportunity") and mathematics learning}

Table 3 provides the explorative correlations between the parental talk and all mathematics learning measures included in the current study. 


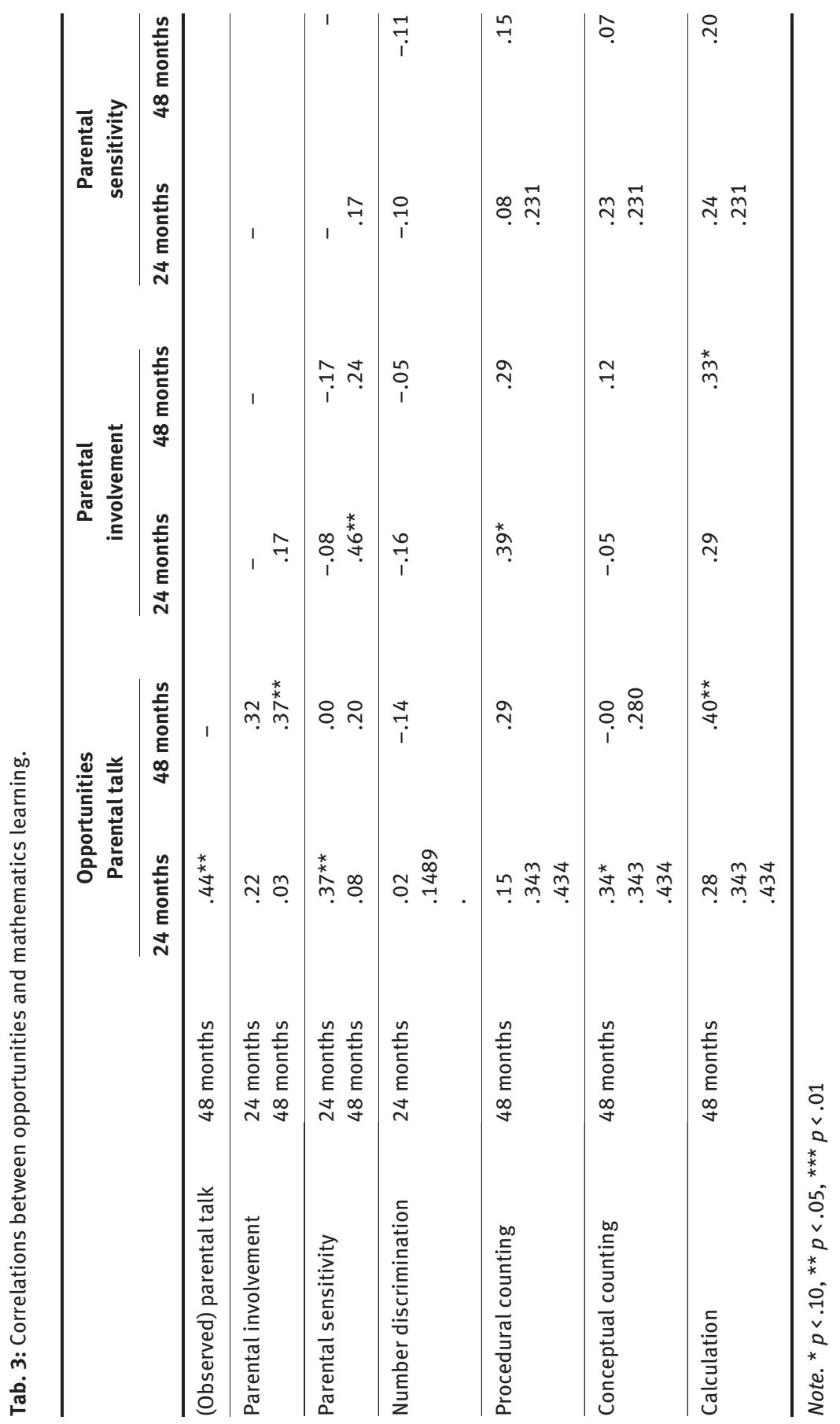


At 48 months, there was a significant and positive linear relationship, $F(1,29)=$ 5.56, $p=.025, R^{2}=.161$ between parental talk and calculation which remained marginally significant in addition to the parental involvement, $F_{\text {change }}(1,28)=$ 3.11, $p=.089, R_{\text {change }}^{2} .09$.

The linear regression analysis with parental talk (observed at 24 months) as the independent variable revealed a relationship and trend of prediction for conceptual counting at 48 months, $F(1,27)=3.60, p=.068$. In addition, although not linear $F(1,27)=2.29, p=.142$, a significant quadratic (positive) relationship could be found, $F(2,26)=3.68, p=.039, R^{2}=.221$ between the parental talk at 24 months and the calculation skills at 48 months.

\section{Discussion}

Parental talk occurred on average about six times per minute during the Duplo or Lego building activity. In line with Susperreguy and Davis-Kean (2016), large differences (varying from 23 to 0 times parental talk) in the amount of math input that children received, were observed. These results indicate a substantial diversity in the amount of parental talk children experience as young children.

In contrast with the finding of Yildiz et al. (2018), in this study there was a significant relationship between parental talk operationalized via questionnaires and via observational methods in toddlers (24 months).

In line with Ramani et al. (2015) and Casey et al. (2018) parental talk was mainly involved in counting and labeling quantities. We observed that parents often focused on small number words with toddlers, whereas Gunderson and Levine (2011) revealed that the indicator "talking about large sets of objects" was the strongest predictor of mathematics learning.

Parental talk was associated with mathematics learning even controlling for parental involvement. In addition, in line with LeFevre et al. (2009), but in contrast with Yildiz et al. (2018), a significant linear relationship was found between more (observed) parental talk and better calculation in kindergarten. As such, the parental numerical language might be perceived as on opportunity factor that stimulates the child's mathematics learning in a positive way. However, it is also possible that parents who talk more about numbers or pick up more opportunities to engage with their children, do so because their children are (initially more) interested in mathematics. Children might, accordingly, provoke numerical parental talk themselves. No causal relationship could be drawn. Nonetheless, the value of parental talk could be demonstrated even when taking into account parental involvement as a plausible explaining factor. 
In addition while the concurrent relationship between the constructs at kindergarten age (48 months) was linear, the relationship at toddler age (24 months) was quadratic in nature. In kindergarten this implied that more parental talk was associated with higher mathematics learning. In toddlerhood, however, it seemed that more parental talk only predicted higher mathematics learning in kindergarten to some extent, needing the appropriate engagement at the right time. At higher rates later mathematics learning declined again. This finding suggests that a child's mathematics learning might not only depend on the parental talk, and empowerment of opportunities should be within children's zone of proximal development. Future research needs to clarify this finding and the clinical relevance more in detail.

There are some limitations to this study. The first limitation is the sample size. A small sample size may lead to higher variability, leading to bias. In addition, only families with a middle or high family income were included. It would therefore be interesting for future research to also take into account low-income families to accurately investigate the influence of SES on both numerical interaction and performance.

Despite the mentioned limitations, the current study might imply that an additional focus on parental talk by agencies in support of parenting could be worthwhile. Making parents aware of the importance of numerical parental talk might empower them and stimulate mathematics learning in young children. However, it may be that education in respect of what is appropriate mathematical talk may be needed.

\section{References}

Anders, Yvonne, Rossbach, Hans-Günther, Weinert, Sabine, Ebert, Susanne, Kuger, Susanne, Lehrl, Simone \& von Maurice, Jutta (2012): Home and preschool learning environments and their relations to the development of early numeracy skills. Early Chilhood Research Quarterly 27, 231-244.

Baten, Elk \& Desoete, Annemie (2018): Mathematical (Dis)abilities within the Opportunity- Propensity Model: The Choice of Math Test Matters. Frontiers in Psychology 9, Art. 667 Developmental Psychology. doi:http://dx.doi.org:10.3389/fpsyg.2018.00667.

Benavides-Varela, Silvia, Butterworth, Brian, Burgio, Francesca, Arcara, Giorgio, Luc Angeli, Daniella \& Semenza, Carlo (2016): Numerical activities and information learned at home link to the exact numercay skills in 5-6 years-old Children. Frontiers in Psychology 8, 94. doi:http://dx.doi.org/10.3389/fpsyg.2016.00094.

Blevins-Knabe, Belinda \& Austin, Ann M Berghout (2016): Early Childhood Mathematics Skill Development in the Home Environment. Cham, Switzerland: Springer International Publishing. doi:https://doi.org/10.1007/978-3-319-43974-7. 
Byrnes, James \& Wasik, Barabara A. (2009): Factors predictive of mathematics achievement in kindergarten, first and third grades: An opportunity - propensity analysis. Contemporary Educational Psychology 34, 167-183.

Byrnes, James P. \& Miller, Dana (2007): The relative importance of predictors of math and science achievement: An opportunity - propensity analysis. Contemporary Educational Psychology 32, 599-629.

Byrnes, James P. \& Miller, Dana (2016): The growth of mathematics and reading skills in segregated and diverse schools: An opportunity-propensity analysis of a national database. Contemporary Educational Psychology 46, 34-51.

Byrnes, J. P. (2020): The potential utility of an opportunity-propensity framework for understanding individual and group differences in developmental outcomes: A retrospective progress report. Developmental Review 56. doi:http://dx.doi.org/10.1016/j.dr.2020.100911.

Casey Beth, M., Lombardi Caitlin, M, Dana, Thomson, Nguyen, Hoa Nha, Paz, M, Theriault Cote, A \& Eric Dearing, E (2018): Maternal support of children's early numerical concept learning predicts preschool and first-grade math achievement. Child Development 89 (1), 156-173.

Ceulemans, Annelies, Baten, Elke, Loeys, Tom, Hoppenbrouwers, Karel, Titeca, Daisy, Rousseau, Sofie \& Desoete, Annemie (2017): The relative importance of parental numerical opportunities, prerequisite knowledge and parent involvement as predictors for early math achievement in young children. Interdisciplinary Education and Psychology, 17-123/1 (1), 6, 12 pp. http://riverapublications.com/assets/files/pdf_files/the-relative-importance-ofparental-numerical-opportunities-prerequisite-knowledge-and-parent-involv.pdf.

Ceulemans, Annelies, Titeca, Daisy, Loeys, Tom, Hoppenbrouwers, Karel, Rousseau, Sofie \& Desoete, Annemie (2015): The sense of small number discrimination: The predictive value in infancy and toddlerhood for numerical competencies in kindergarten. Learning and individual differences 39, 150-157.

Claessens, Amy \& Engel, Mimi (2013): How important is where you start? Early mathematics knowledge and later school success. Teachers College Record 115, 1-29.

Clements, Douglas \& Sarama, Julie (2014): The importance of early years. In Slavin, R.E. (ed.): Scinece, Technology \& Mathematics (STEM). Thousand Oaks, CA: Corwin, 5-9.

Deary, Ian J., Whalley, Lawrence J., Lemmon, Helen, Crawford, J. R. \& Starr, John M. (2000): The stability of individual differences in mental ability from childhood to old age: Follow-up of the 1932 Scottish mental survey. Intelligence 28 (1), 49-55.

Desoete, Annemie, Stock, Pieter, Schepens, Annemie, Baeyens, Dieter \& Roeyers, Herbert (2009): Classification, Seriation, and Counting in Grades 1, 2, and 3 as Two-Year Longitudinal Predictors for Low Achieving in Numerical Facility and Arithmetical Achievement? Journal of Psychoeducational Assessment 27, 252-264.

Dieterich, Susan E., Assel, Michael, Swank, Paul R., Smith, Karen E. \& Landry, Susan H (2006): The impact of early maternal verbal scaffolding and child language abilities on later decoding and reading comprehension skills. Journal of School Psychology 43, 481-494.

Dowker, Ann (2019): Individual Differences in Arithmetic: Implications for Psychology, Neuroscience and Education, 2nd edition. Hove: Psychology Press.

Dowker, Ann, De Smedt, Bert \& Desoete, Annemie (2019): Editorial: Individual differences in arithmetical development. Frontiers in Psychology 10, 2-13. doi:https://doi.org/10.3389/ fpsyg.2019.02672.

Dreyer, Bernard P., Medelsohn, Alan.L \& Tamis-LeMonda, Catherine S (1996): Assessing the child's cognitive home environment through parental report: Reliability and validity. Early Development \& Parenting 5, 271-287. 
Duncan, Greg J \& Katherine Magnuson, K. (2011): The nature and impact of early achievement skills, attention skills, and behavior problems. In Duncan, Greg J., Murnane, R. J. (eds.): Whither Opportunity: Rising Inequality, Schools, and Children's Life Chances. Russel Sage, The Russell Sage Foundation New York, 47-69.

Feigenson, Lisa \& Carey, Susan (2005): On the limits of infants' quantification of small object. Cognition 97, 295-313.

Feldman, Robert S. (1998). Coding interactive behavior manual. (unpublished manual). Bar-Ilan University, Israel.

Feldman, Robert S \& Shafiq Masalha, S. (2010): Parent-child and triadic antecedents of children's social competence: Cultural specificity, shared process. Developmental Psychology 46, 455-467. doi:10.1037/a0017415.

Geary, David (2011): Consequences, characteristics, and causes of mathematical learning disabilities and persistent low achievement in mathematics. Journal of Developmental \& Behavioral Pediatrics 32 (3), 250-263.

Grégoire, Jacques, Noël, Marie Pascale, Catherine \& liVan Nieuwenhoven, C. (2004): TEDIMATH. Antwerpen: Harcourt.

Gunderson, Elizabeth A \& Levine, Susan C. (2011): Some types of parent number talk count more than others: Relations between parents' input and children's cardinal-number knowledge. Developmental Science 14, 1021-1032.

Hong, Sehee, Yoo, Sung-Kyung, You, Sukkyung \& Chih-Chun, Wu (2010): The reciprocal relationship between parental involvement and mathematics achievement: Autoregressive cross-lagged modeling. The Journal of Experimental Education 78, 419-439.

Karrass, Jan \& Braungart-Rieker, Julia M. (2005): Effects of shared parent infant book reading on early language acquisition. Journal of Applied Developmental Psychology 26, 133-148.

Kleemans, Tijs, Peeters, Marieke, Segers, Eliane \& Verhoeven, Ludo (2012): Child and home predictors of early numaneracy skills in kindergarten. Early Childhood Research Quarterly 27, 471-477.

LeFevre, Jo-Anne, Skwarchuk, Sheri-Lynn, Smith-Chant, Brenda L., Fast, Lisa A., Kamawar, Deepthi \& Bisanz, Jeffrey (2009): Home numeracy experiences and children's math performance in the early school years. Canadian Journal of Behavioural Science 41, 55-66.

Levine, Susan C, Suriyakham, Linda Whealton, Rowe, Meredith L, Huttenlocher, Janellen \& Gunderson, Elizabeth A (2011): What counts in the development of young children's number knowledge? Developmental Psychology 47, 302-302.

Melhuish, Edward \& Phan, Mai B. (2008): Effects of the home learning environment and preschool center experience upon literacy and numeracy development in early primary school. Journal of Social Issues 64, 95-114.

Missall, Kirsten, Hojnoski, Robin, Caskie, Grace I.L. \& Repasky, Patrick (2015): Home numeracy environments of preschoolers: Examining relations among mathematical activities, parent mathematical beliefs, and early mathematical skills. Early Education and Development 26, 356-376.

Nelson, Gena \& Powell, Sarah R (2018): A systematic review of longitudinal studies of mathematics difficulty. Journal of Learning Disabilities 51, 523-539. doi:https://doi.org/ $10.1177 / 0022219417714773$.

Niklas, Frank, Cohrssen, Caroline \& Tayler, Colette (2016): Improving preschooler's numerical abilities by enhancing the home numeracy environment. Early Educaton and Development $27,372-383$. 
Ramani, Geetha B, Rowe, Meredith L, Eason, Sarah H \& Leech, Kathryn A (2015): Math talk during informal learning activities in Head Start families. Cognitive Development 35, 15-33.

Ritchie, Stuart I \& Bates, Timothy C (2013): Enduring links from childhood mathematics and reading achievement to adult socioeconomic status. Psychological Science 24, 5-7. doi: https://doi.org/10.1177/0956797612466268.

Segers, Eliane, Kleemans, Tijs \& Verhoeven, Ludo (2015): Role of parent literacy and numeracy expectations and activities in predicting early numeracy skills. Mathematical Thinking and Learning 17, 219-236.

Skwarchuk, Sheri-Lynn, Sowinksi, Carla \& LeFevre, Jo-Anne (2014): Formal and informal home learning activities in relation to children's early numeracy and literacy skills: The development of a home numercay model. Journal of Experimental Child Psychology 121, 63-84.

Stock, Pieter, Desoete, Annemie \& Roeyers, Herbert (2009): Mastery of the counting principles in toddlers: A crucial step in the development of budding arithmetic abilities? Learning and Individual Differences 19, 419-422.

Susperreguy, Maria Ines \& Davis-Kean, Pamela (2016): Maternal math talk in the home and math skills in preschool children. Early Education and Development 9289, 1-17.

Sy, Susan R, Gottfried, Allen W. \& Gottfried, Adele Eskeles (2013): A transactional model of parental involvement and children's achievement from early childhood through adolescence. Parenting Science and Practice 13, 133-152.

Wang, Aubrey H., Shen, Feng \& Byrnes, James P (2013): Does the opportunity-propensity framework predict the early mathematics skills of low-income pre-kindergarten children? Contemporary Educational Psychology 38, 259-270.

Wechsler, David (2002): Wechsler Preschool and Primary Scale of Intelligence - Third Edition. Dutch Translation by Hendriksen,J., \& Hurks, P. Amsterdam, Nederland: Pearson.

Wilder, Sandra (2014): Effects of parental involvement on academic achievement: A meta-synthesis. Educational Review 66, 377-397.

Wilson, Anna J, Andrewes, Stuaert G., Struthers, Helena, Rowe, Victoria M., Bogdanovic, Rajna \& Waldie, Karen E. (2015): Dyscalculia and dyslexia in adults: Cognitive bases of comorbidity. Learning and Individual Differences 37, 118-132.

Xu, Fei \& Arriaga, Rosa I. (2007): Number discrimination in 10-month-old infants. British Journal of Developmental Psychology 25, 103-108.

Yildiz, Belde Mutaf, Delphine, Sasanguie, Bert, De Smedt \& Bert Reynvoet, B. (2018): Investigating the relationship between two home numeracy measures: A questionnaire and observations during lego building and book reading. British Journal of Developmental Psychology 36, 354-370.

Zhou, Xin, Huang, Jim, Wang, Zhengke, Wang, Bin, Zhao, Zhenguo, Yang, Lei \& Yang, Zhengzheng (2006): Parent-child interaction and children's number learning. Early Child Development and Care 176, 763-775. 